\title{
Landslide Disaster Risk Reduction Strategies and Present Achievements in Sri Lanka
}

\author{
R.M.S Bandara and Pathmakumara Jayasingha \\ National Building Research Organization, 99/1, Jawatta road, Colombo 05, Sri Lanka \\ Email:jpathmak@gmail.com
}

\begin{abstract}
A significant impact on the economy and the social context of Sri Lanka has been caused by hydro-meteorologically induced landslides. Though many organizations are working on landslide studies, National Building Research Organization (NBRO) is the key organization that involves in landslide research and risk reduction programs in Sri Lanka. This paper discusses about the present strategies set to reduce the landslide risk and the present achievements. Landslide risk reduction process has been strategized in number of ways which follow basic guidelines of disaster management. The strategic plan developed by NBRO includes following main components/activities; such as identification, awareness, early warning, mitigation and low enforcement. Implementation of those strategies have resulted Landslide Hazard Zonation Maps through Landslide Hazard Zonation Mapping Program, establishment of real time early warning system, declaring landslide prone areas and introducing land clearance process and successful completion of landslide mitigation projects with improvement of technological knowledge.
\end{abstract}

Keywards: Landslides and land subsidence in Sri Lanka, central highland, NBRO, landslide risk reduction strategies, present achievements

\section{Introduction}

Landslides which are hydro-meteorologically induced have become a frequent natural hazard in Sri Lanka and hence, overcoming the threat of landslides is really a challenge to the geologists working on landslides, disaster management sector and the administrators in the country $[1,2]$. Due to the northeast and the southwest monsoon and also sometime by unexpected extreme weather conditions, the central highland of the country is highly disturbed and destructed due to land slide occurrences and human lives of the affected areas are seriously suffered [3, 4]. Hence it is well understood that the landslide disasters in Sri Lanka are causing a significant economic loss which seriously affects the GDP of the country and there is urgent need and essential requirement of landslide risk reduction.

$20 \%$ of the landmass of the country is covered with the mountainous and hilly regions. Sri Lanka is composed of mostly high grade metamorphic rocks which contains high amount of feldspar and flaky minerals $[5,6]$. Hence high weathering and soil formation rates in Sri Lanka, even since it is an island in tropical environment, create massive and thick unstable soil profiles which are trigged by heavy rains to cause landslides in central highlands [7].

The central highland is covered with 12 districts and most of the places of these districts are prone to landslide hazard (Figure 1). Though some of the landslides have been initiated by natural causes, it seems that human impact on improving the potential is also considerable. Unfortunately, $30 \%$ of the total population of the country live in these mountainous areas [8]. It is well understood and identified that with the increase of highland population; the land use pattern has been dramatically changed. Therefore, it has caused the triggering of the mass movements and cutting failures increasingly in most of the places of the highland recently.

Depending on the monsoon and extreme weather conditions prevailed so far, the affected part of the central highland in each season has been changed. Therefore the precise weather forecasting is needed in forecasting of areas with landslide risk in each rainy seasons in the country. The recent landslides occurred in the year 2003, 2007, 2010, 2011, 2012, 2014, 2015 and 2016 had taken nearly 1000 human lives in the country (Figure 2). 
Land subsidence due to natural causes such as formation of underground cavities due to carbonate rock weathering is another geo hazard occurring in the areas such as Matale and Jaffna peninsula in the country [3].

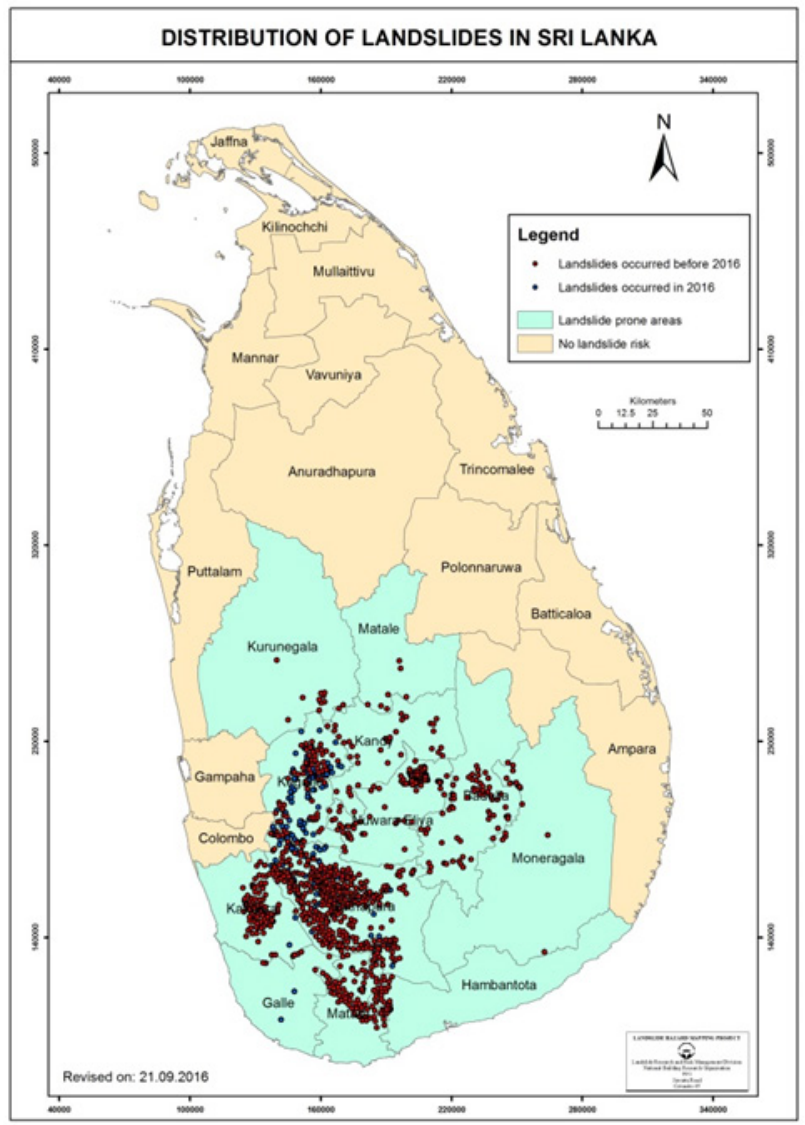

Figure 1. Distribution of past landslides in Sri Lanka

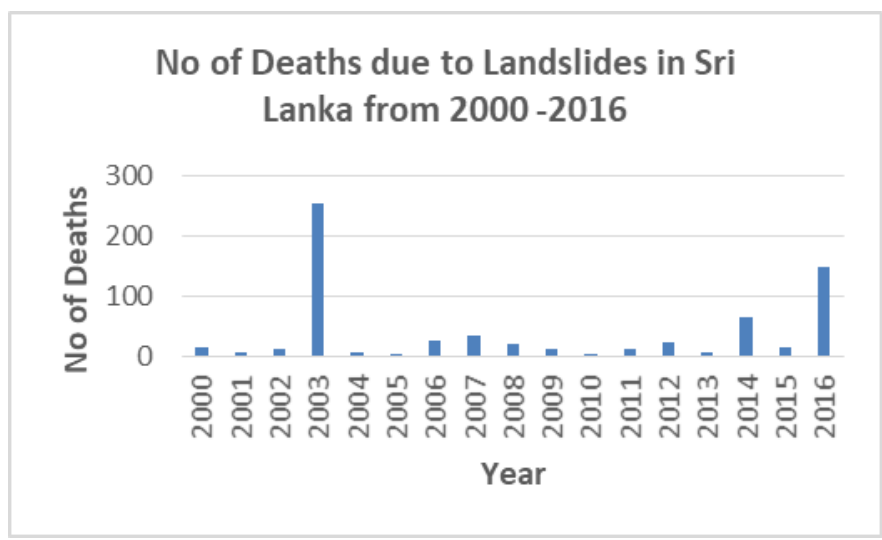

Figure 2. Number of deaths due to landslide hazard in Sri Lanka from 2000-2016

\section{Historical Background of Landslide Research in Sri Lanka}

The landslide studies in Sri Lanka have been dated back to 1980. After the disastrous landslides that occurred in the mid-1980s, the Government of Sri Lanka took the initiatives of studying the landslide phenomena in the country. National Building Research Organization (NBRO) which has been 
established in 1985 was selected as the executing agency and was entrusted with the management of landslide hazard risk in Sri Lanka.

The National Building Research Organisation (NBRO) of Sri Lanka which was mainly to conduct building research in Sri Lanka and geotechnical research initiated a pioneering work of landslide hazard zonation mapping program (LHZMP) with the assistance of UNDP in 1990 [9]. The hazard zonation mapping initially was conducted for two districts naming Badulla and Nuwaraeliya. The land areas of the mountainous and hilly areas in those districts were characterized into three hazard zones such as high, medium and low hazard zones according to geology, hydrology, slope, landform, soil type and the thickness\& land use pattern. Finally the hazard zonation mapping program has been extended for 12 landslide prone districts including Kegalle, Matale, Kandy, Kalutara, Matara, Galle, Hambantota, Moneragala and Kurunegala.

Since then, the government with the help of NBRO has undertaken various preparedness and mitigation measures such as: landslide hazard zonation mapping; regulation of land use and development activities in hilly terrains; capacity building of stakeholder agencies; public awareness and education of the developers and land users; rescue, disaster relief rehabilitation and resettlement of the affected persons $[9,10,11,12,13,14]$. The NBRO work have been duly recognized by the stakeholders and the Government of Sri Lanka by providing regulating power of land development, building and construction activities in 15 landslide prone districts of the country at the moment.

\section{Landslide Disaster Risk Reduction Strategies in Sri Lank}

Presently NBRO has initiated a multidisciplinary approach for landslide risk reduction. The strategies presently applying include identification, awareness, early warning, mitigation and low enforcement.

\subsection{Landslide Hazard Zonation Mapping}

Identification of landslide potential areas which have been carried out under the landslide hazard zonation mapping program is in two folds and it includes a desk study followed by a field clarification $[9,10]$. Having several map layers of geology, slope, soil overburden, hydrology, landform and land use pattern, different weightages and ratings based on expert opinion and statistical analysis of historical data are given for each category of each layer. The derived maps are overlaid by using GIS to form hazard zonation map which is in 1:10000 scale. After that, a field clarification is carried out and fine tuning is done according to the necessary adjustments (Figure 3A). Presently 1:10000 scale hazard zonation maps are being prepared. The prepared 1;10000 maps have been distributed among the local authorities and have been made available to any person or any institute at any time. Recently the prediction power of the hazard zonation maps has been assessed and found that more than $90 \%$ of prediction power was achieved [15].

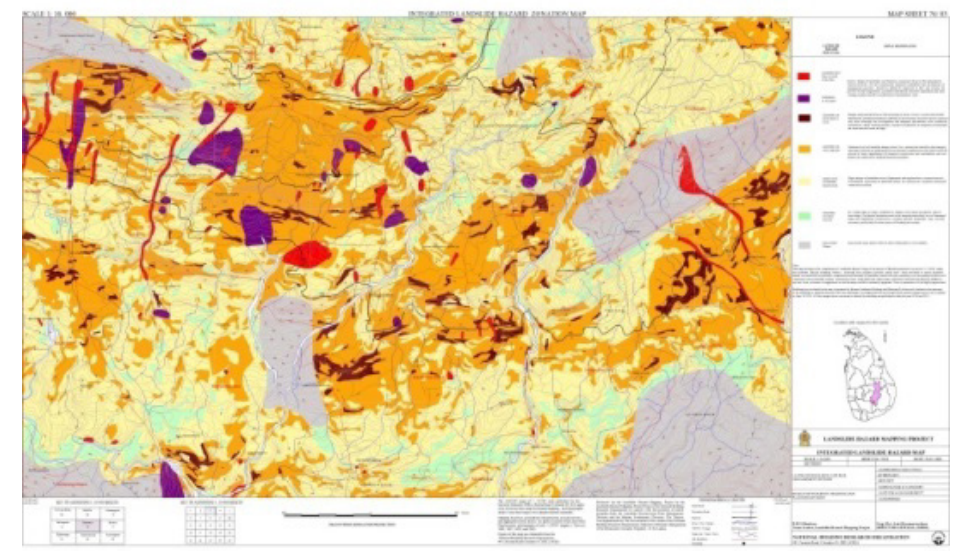

A 


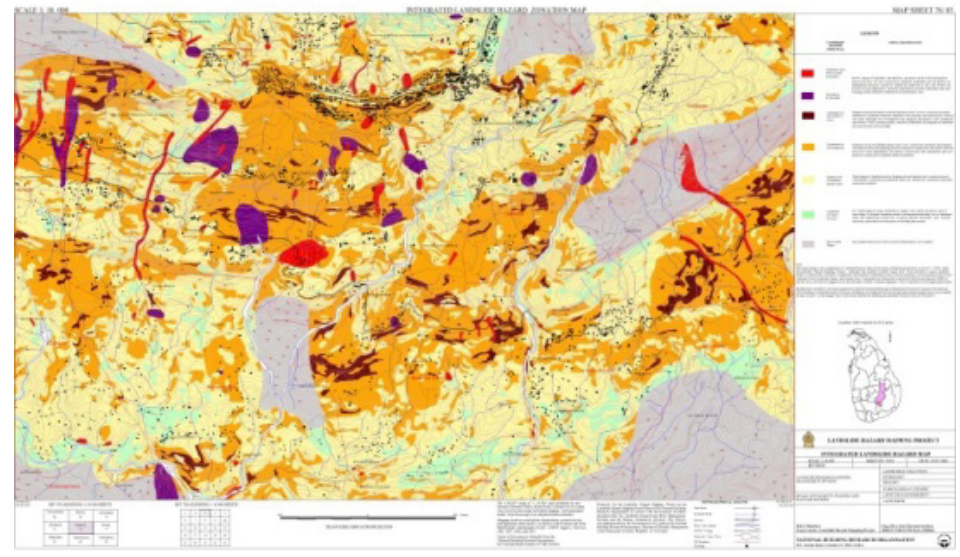

B

Figure 3. 1:10000 scale landslide hazard zonation map (A) and exposure Map (B).

Based on the landslide hazard zonation maps, the central highland has been categorized into three hazard zones; high, medium and low hazard zones (Figure 4). The people living within the high hazard zones are strongly advised to move away from the landslide potential sites. No future development or construction is allowed in these high hazard areas. Identified potential sites which are in medium hazard zones are forwarded for mitigation process and at the same time people are made aware and alert. Landslide Risk identification was further strengthen by developing Risk assessment guidelines with overlaying extra information above the hazard zonation map such as expose map and the flow path boundaries (Figure 3B).

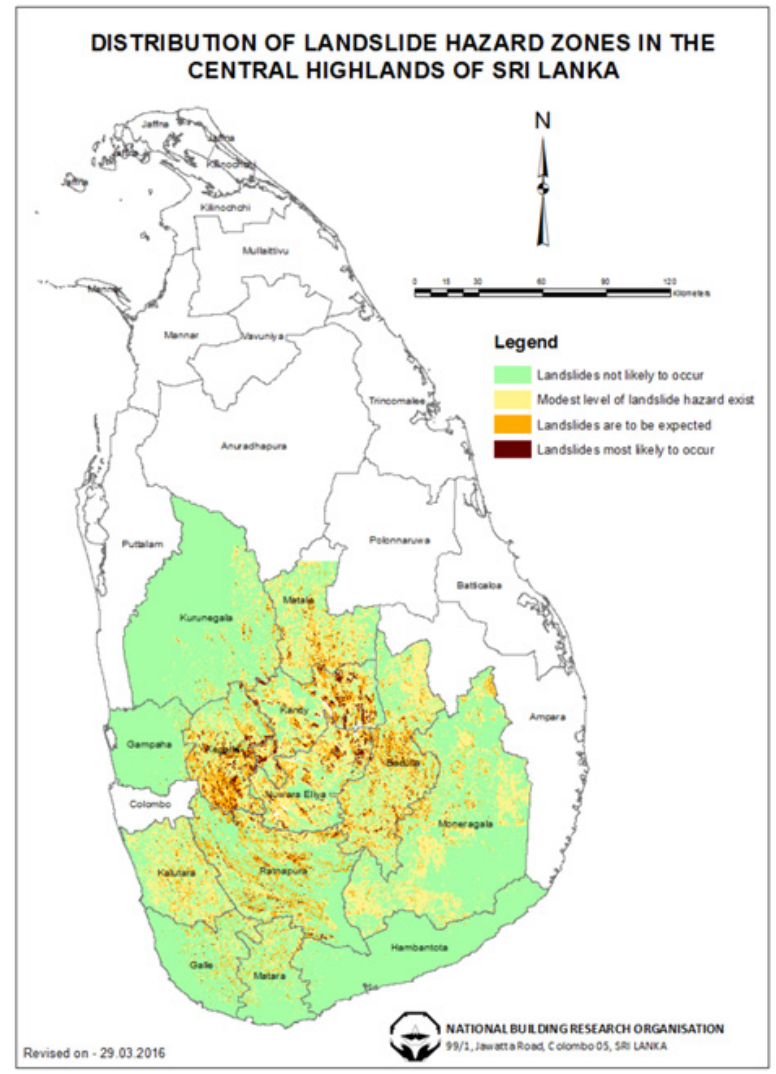

Figure 4. Landslide hazard zones in central highland of Sri Lanka 
In addition, awareness programs on landslide risk reduction are conducted for public, administrators, government officers, security forces and various other institutes in the country.

\subsection{Real Time Early Warning for Landslide Vulnerability}

Early warnings are issued based on real time rainfall data, especially for the previously identified potential landslide areas. The real time data are gathered from automated rain gauges installed in 160 locations covering entire highland of the country. Evacuation notice to public in landslide potential areas is given after having $150 \mathrm{~mm}$ rainfall per 24 hours of period [12]. Localized threshold limit calculation are being processed with the present climatic change phenomenon in south Asian countries (Figure 5) $[16,17]$. It was revealed that the final evacuation warning should be $150 \mathrm{~mm}$ rain per 24 hours period [12]. All the early warning messages are distributed by using local media.

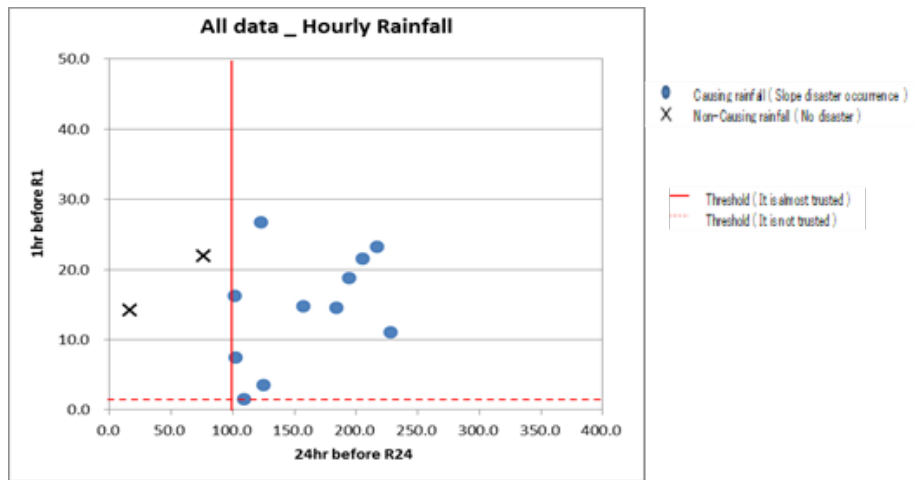

Figure 5. Threshold limits by hourly rainfall calculated by the recent landslide events May 2016 for Kegalla district, Sri Lanka

\subsection{Landslide Mitigation}

Identification of landslide in central highland leads categorization which is important in setting selection criteria for mitigation. Mitigation of landslide has been started in 2006 in Sri Lanka and it was a new approach in technological development in NBRO and other related institutes in the country. The first mitigation project has been focused to reduce the landslide risk reduction in townships such as Peradeniya and Padiyapalalla. Those two projects were highly successful and hence more mitigation projects have been launched with the auspicious of the government. Due to various developments in the road sector including widening, small scale failures were occurred in the major roads in the country during the last decades. Mitigation was extended to road sector with the funding support of World Bank project called "Climate Resilient and Improvement Project" (CRIP) and JICA project known as Landslide Disaster Prevention Project (LDPP)[18]. In addition, some burning issues related to unstable slopes and land instability in major schools were addressed under the project CRIP (Figure 6). Addition to the above initiations Sri Lankan Government has allocated separate budget to NBRO take necessary steps to mitigate landslide vulnerable locations which are threaten to the Sri Lankan community[19]. The land subsidence issues in Matale and Jaffna peninsula have been studied with the technical support of Norway and zoning of high hazard subsidence areas are being process at the moment.

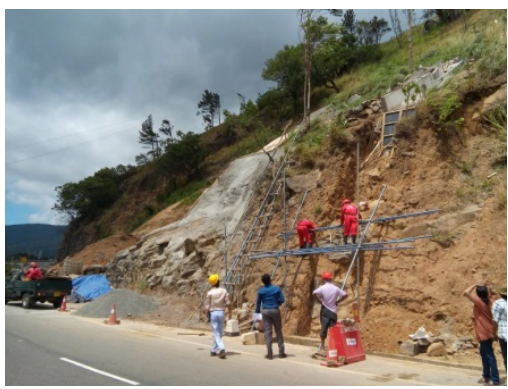

A 


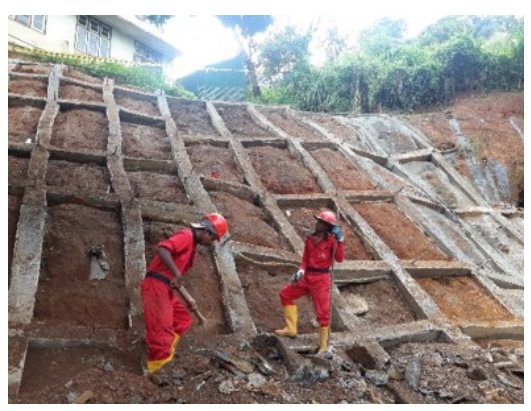

$\mathrm{B}$

Figure 6. Mitigation activities going on A. in Kandy-Mahiyanganaya road B in Mahamaya School in Kandy under the supervision of NBRO.

Most of the mitigation works carried out were involved in structural mitigation measures where concrete and steels were used. Recently application of bioengineering techniques are being considered $[20]$.

\subsection{Introduction of Construction Guidelines for Construction and Development}

The landslide risk reduction process in Sri Lanka has been strengthened by low enforcements. Any individual or institute or organization doing any constructions in declared landslide potential districts must have NBRO certificate on suitability of land with regard to landslide potential. In the areas of medium and low hazard, constructions and developments are allowed under the guidelines given by NBRO and their close supervision.

\section{Present Achievements in Sri Lanka}

The strategies developed for landslide rick reduction in the country so far has given excellent results in saving human life and infrastructure facilities. The conducted awareness programs have greatly improved the consciousness about the landslide risk. The people in most of the risk areas have well prepared to face the threat at any time. Strengthening of unstable slopes and lands in road and school sector has led to smooth functioning and saving human lives. Hence it has decreased the sudden or unnecessary loss of money and infrastructure securing the counties GDP.

Recent decisions taken from the government to permanently relocate the people from landslide vulnerable locations according to the instructions and guidelines and settle them in safer places with NBRO recommendations was a good achievement to the NBRO. It was further revealed that the decision taken to revise the NBRO act to include all type of authorities to control and prevent landslide vulnerability in Sri Lanka. Further to that it was a vast gap on data base development on landslide, even though the NBRO has more than twenty five years on landslide. Hence recently a data sharing software has been developing.

Acknowledgments. We would like to thank Dr. Asiri Karunawardhana, Director General of NBRO for his straight forward guidance and support given at any time. This type of results and achievements could not be fulfil without the all type of supporting staff in Landslide Research and Risk Management Division, therefore our hearties gratitude has to go them.

\section{References}

1. P. Jayasingha, "Social Geology and Landslide Disaster Risk Reduction in Sri Lanka", Journal of Tropical Forestry and Environment, Vol. 6, no. 2, 2016.

2. G.J.M.S.R. Jayasinghe, P. Wijekoon and J. Gunatilake, "Landslide susceptibility assessment using statistical models: A case study in Badulla district, Sri Lanka", Ceylon Journal of Science, Vol. 46, no. 4, pp. 26-41, 2017. 
3. P. Jayasingha, R.M.S. Bandara, G. Jayathissa, W.S. Weliange, R.A.L. Osborne, A.S. Dandeniya, P. Algiriya, S. Senanayake, M. Champika and N.S. Prasannajith, "Landslide and subsidence potential due to the progressive development of cave network in Ella-Wellawaya area, Sri Lanka" 20th International forestry and environment symposium, 16th and 17th October, 2015, Club Hotel Waikkal, Negombo. Department of Forestry and Environmental Science, University of Sri Jayawardhanapura, Sri Lanka. 2015, pp. 113. 2015.

4. U. Ratnayake and S. Herath, "Changing rainfall and its impact on landslides in Sri Lanka", Journal of Mountain Science, Vol. 2, no. 3, pp 218-224, 2005.

5. P.G. Cooray, "The Precambrian of Sri Lanka: a historical review", Precambrian Research, Vol. 66, pp. 3-18, 2004.

6. P. Jayasingha, W.S. Weliange, A.S. Dandeniya and P. Elgiriya, "A classification for Sri Lankan caves" Proceedings of National Archaeological Symposium, 2010, Department of Archaeology, Sri Lanka. Vol.2. pp. 181192, 2010.

7. T. Hewawasam, F. Blanckenburg, M. Schaller and P. Kubik, "Increase of human over natural erosion rates in tropical highlands constrained by cosmo genic nuclides", Geology, Vol. 31 no. 7, pp. 597-600, 2003.

8. Department of Census and Statistic, Sri Lanka. http://www.statistics.gov.lk

9. Manual on Landslide Hazard Zonation Landslide Hazard Mapping Project, NBRO, 1989.

10. Manual on Field Mapping for Landslide Hazard Zonation - Landslide Hazard Mapping Project, NBRO - 1989.

11. Proceedings of the National Symposium on Landslides in Sri Lanka, National Building Research Ogranization, 1994.

12. R.M.S. Bandara, "Landslide Early warning in Sri Lanka", Regional seminar on experience of geotechnical investigations and mitigation for landslides, Bangkok, Thailand, pp 13-14, 2008

13. Manual of Landslide Instrumentation, General considerations and measurement of landslide activity, NBRO,UNDP-LHMP SLR 89/001. 1995.

14. Construction in hilly regions of Sri Lanka, Site selection, monitoring and developmental planning, NBRO,UNDP-LHMP SLR 89/001, 1995.

15. R.M.S.D. Rajapaksha, M.A.K. Kumari, and H.K.D.W.M.I.U.K. Hapuhinna, "Assessing the Predictive Power of Existing Landslide Hazard Zonation Methodology: A Case Study - Rathnapura and Kalutara Districts" $8^{\text {th }}$ Annual NBRO symposium, 2017.

16. E.N.C. Perera, D.T. Jayawardana, and P. Jayasingha, "A Rainfall Intensity-Duration Threshold for Landslides in Badulla, Sri Lanka", Journal of Geoscience and Environmental Protection, Vol. 5, no. 12. 2017.

17. U.L.N.I. Liyanage, R.M.S. Bandara, H.M.L. Indrathilake, and L. Iwasaki, "Threshold limits on slope disaster events in May, 2016: Case study from Kegalle district in Sri Lanka" $7^{\text {th }}$ Annual NBRO Symposium, 2016.

18. W.A.D.T.L. Wijesinghe, J,M,C,K, Jayasundara, R. Balasooriya, D.M.D.S. Dissanayake, K.N. Bandara and P. Jayasingha, "Geotechnical and Geological Characterization of Kahagalla Earth Slip for Mitigation Purpose", $7^{\text {th }}$ Annual NBRO Symposium, 2016.

19. W.A.D.T.L. Wijesinghe, B. Abeywickrama, D.M.D.S. Dissanayake, P. Jayasingha and K.N. Bandara, "Introducing of Vernonia Elaeagnifolia (Curtain Creeper) to the Cut Slop at Diyatalawa, Sri Lanka to Improve the Aesthetic View" th $^{\text {th }}$ Annual NBRO Symposium, 2016.

20. A.D.H. Balasuriya, P. Jayasingha and W.A.P.P. Christoper, "Application of Bioengineering to slope stabilization in Sri Lanka with special reference to Badulla District", The Professional Geologist, D.M.D.S. ol.55, no.2, pp 47-51, 2018. 